\title{
Fluorine-vacancy defects in fluorine-implanted silicon studied by electron paramagnetic resonance
}

\author{
T. Umeda, ${ }^{1, a)}$ J. Isoya, ${ }^{1}$ T. Onshima, ${ }^{2}$ S. Onoda, ${ }^{2}$ N. Morishita, ${ }^{2}$ K. Okonogi ${ }^{3}$ and \\ S. Shiratake ${ }^{3}$ \\ ${ }^{1}$ University of Tsukuba, Tsukuba 305-8573, Japan \\ ${ }^{2}$ Japan Atomic Energy Agency, Takasaki 370-1292, Japan \\ ${ }^{3}$ Elpida Memory, Inc., Higashihiroshima 739-0198, Japan
}

(Received 29 December 2009; accepted 11 July 2010; published online 30 July 2010)

\begin{abstract}
An electron paramagnetic resonance (EPR) study on fluorine-vacancy defects $\left(\mathrm{F}_{n} V_{m}\right)$ in fluorine-implanted silicon is demonstrated. Fluorine implantation is an important technology for $\mathrm{Si}$ microdevices and EPR measurements showed that this process created a variety of $\mathrm{F}_{n} V_{m}$ defects of different sizes $\left(V_{2}, V_{4}\right.$, and $\left.V_{5}\right)$. In $\mathrm{F}_{n} V_{m}$, a Si-F bond exhibited a different chemical nature compared to a $\mathrm{Si}-\mathrm{H}$ bond in hydrogen-vacancy complexes. The most primitive defect was $\mathrm{F} V_{2}$ (F0 center) and the final types were $\mathrm{F}_{n} V_{5}$ (F1 center) and $\mathrm{F}_{n} V_{2}$ (F2 center) which increased in annealing processes as low temperature as $200{ }^{\circ} \mathrm{C}$. (C) 2010 American Institute of Physics. [doi:10.1063/1.3473763]
\end{abstract}

Fluorine forms a strong bond with silicon, ${ }^{1}$ similar to hydrogen $(\mathrm{Si}-\mathrm{H})$, which is useful for $\mathrm{Si}$ technologies. ${ }^{2}$ Fluorine also has great benefits for suppressing transient enhanced diffusion of boron atoms. ${ }^{1,3-6}$ This property is believed to be due to the formation of fluorine-vacancy defects $\left(\mathrm{F}_{n} V_{m}\right)$, which suppress the activity of interstitial (I)-type defects interacting with boron atoms. ${ }^{1,3,4}$ First-principles calculations predicted that the most stable $\mathrm{F}_{n} V_{m}$ defects are $\mathrm{F}_{4} V$ or $\mathrm{F}_{6} V_{2}$ which are fully passivated by $\mathrm{F}$ atoms. ${ }^{1,3,4}$ On the other hand, positron annihilation spectroscopy (PAS) revealed two preferential sizes of vacancies (approximately $V_{2}$ or $\left.V_{4}\right)^{5,6}$ Secondary ion mass spectroscopy showed a high threshold temperature $\left(\sim 550{ }^{\circ} \mathrm{C}\right)$ for fluorine diffusion, ${ }^{5}$ suggesting that $\mathrm{F}$ atoms become immobile due to strong $\mathrm{Si}-\mathrm{F}$ bonds in $\mathrm{F}_{n} V_{m}$.

In this Letter, we present a different approach to investigate fluorine and $\mathrm{F}_{n} V_{m}$ defects using electron paramagnetic resonance (EPR), which provides a more concrete view of fluorine behaviors in $\mathrm{Si}$. We found at least four types of paramagnetic $\mathrm{F}_{n} V_{m}$ defects of different sizes $\left(V_{2}, V_{4}\right.$, and $\left.V_{5}\right)$ in as-implanted and in subsequently annealed Si. Using EPR, their behavior could be studied individually as follows: (1) two distinct types $\left(V_{2}\right.$ and $\left.V_{5}\right)$ were stable, providing microscopic models for the previous PAS data, (2) a different nature of the $\mathrm{Si}-\mathrm{F}$ bond was found in comparison with the $\mathrm{Si}-\mathrm{H}$ bond, and (3) low-temperature motion $\left(<20{ }^{\circ} \mathrm{C}\right)$ and diffusion $\left(\sim 200{ }^{\circ} \mathrm{C}\right)$ of $\mathrm{F}_{n} V_{m}$ were revealed.

The starting substrates $\left(0.3 \times 0.8 \times 0.01 \mathrm{~cm}^{3}\right)$ were phosphorus-doped float zone $\mathrm{Si}(100)$ with a high resistivity $(>1000 \Omega \mathrm{cm})$ and integrated-circuits-grade $30-\mathrm{cm}-$ diameter Czochralski-Si(100) with an epitaxial layer and phosphorus or boron doping (5-15 $\Omega \mathrm{cm}$ ). For the former wafers, multiple $\mathrm{F}$ implantation was performed on both of their wide faces by $5 \times 10^{11}$ to $5 \times 10^{14} \mathrm{~F} / \mathrm{cm}^{2}$ with 7.5 to 15 $\mathrm{MeV}$, which was designed for high-sensitive EPR measurements. A more realistic (shallow and single) $\mathrm{F}$ implantation ${ }^{2,3,6}$ was examined on the latter wafers by 1 $\times 10^{12}$ to $1 \times 10^{14} \mathrm{~F} / \mathrm{cm}^{2}$ with $20 \mathrm{keV}$. These two processes created $\mathrm{F}$ profiles as shown in the inset of Fig. 1. After di-

${ }^{a)}$ Electronic mail: umeda@bk.tsukuba.ac.jp. luted hydrogen fluoride treatments on the sample surfaces, EPR spectra were measured using a Bruker Bio-Spin E500 $\mathrm{X}$-band spectrometer with $100 \mathrm{kHz}$ magnetic-field modulation of 0.05 to $0.1 \mathrm{mT}$ width.

EPR spectra of six samples are shown in Figs. 1(a)-1(e). In the lowest-dose sample (a), no significant effects of $F$ were detected. The spectrum is dominated by the well-

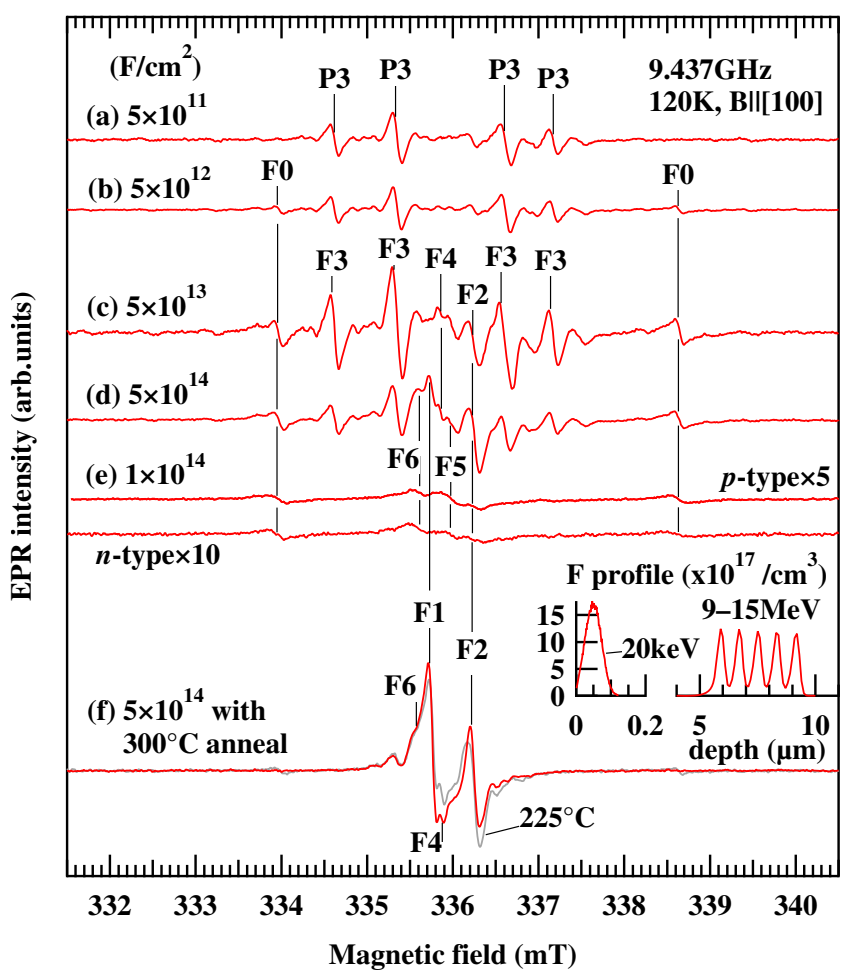

FIG. 1. (Color online) EPR spectra of F-implanted Si. F doses are (a) $5 \times 10^{11} \mathrm{~F} / \mathrm{cm}^{2}$ at 6 energies, (b) $5 \times 10^{12} \mathrm{~F} / \mathrm{cm}^{2}$ at 5 energies, (c) $5 \times 10^{13} \mathrm{~F} / \mathrm{cm}^{2}$ at 5 energies, (d) $5 \times 10^{14} \mathrm{~F} / \mathrm{cm}^{2}$ at 3 energies, (e) $1 \times 10^{14} \mathrm{~F} / \mathrm{cm}^{2}$ at $20 \mathrm{keV}$ (for $p$ - and $n$-type wafers), and (f) with isochronal annealing $\left(225\right.$ and $\left.300{ }^{\circ} \mathrm{C}\right)$. The inset shows $\mathrm{F}$ profiles for the $20 \mathrm{keV}$ $\left(1 \times 10^{13} \mathrm{~F} / \mathrm{cm}^{2}\right)$ and high-energies $\left(5 \times 10^{13} \mathrm{~F} / \mathrm{cm}^{2}\right)$ implantations simulated by the SRIM code. Peak F densities are (a) $1.2 \times 10^{16}$, (b) $1.2 \times 10^{17}$, (c) $1.2 \times 10^{18}$, (d) $1.2 \times 10^{19}$, and (e) $1.7 \times 10^{19} \mathrm{~F} / \mathrm{cm}^{3}$. Labels of F0 to F6 indicate a series of new EPR centers originating from $\mathrm{F}_{n} V_{m}$ defects. In (a) and (b), a weak signal at $336.2 \mathrm{mT}$ was different from F2, judging from its isotropic angular dependence. It is probably due to a surface-damage center 


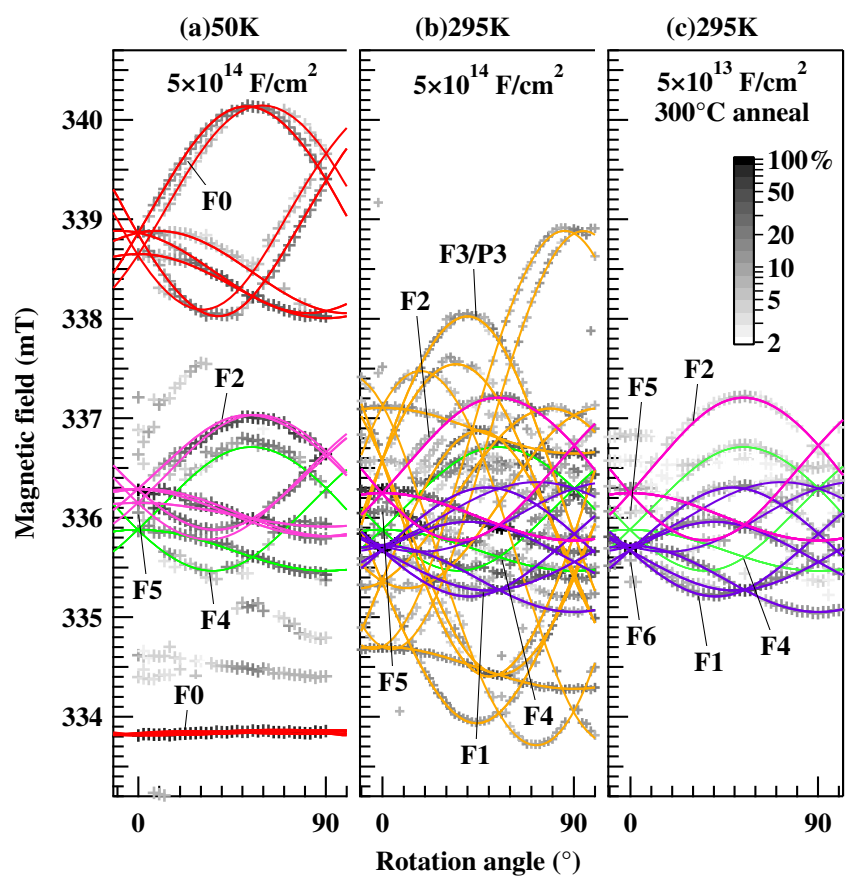

FIG. 2. (Color online) Angular maps of F0-F4 centers $\left(\mathrm{F}_{n} V_{m}\right.$ defects) at $9.437 \mathrm{GHz}$. Magnetic field was rotated from [100] $\left(0^{\circ}\right)$ to $[011]\left(90^{\circ}\right)$. Gray symbols indicate experimental peak positions and their normalized intensities (the largest peak $=100 \%$ ) are expressed by a gray scale shown in inset. Solid lines are simulated by SH parameters in Table I. There are still untraced angular maps (e.g., F5 and F6), suggesting more variety of minor $\mathrm{F}_{n} V_{m}$ defects.

known P3 center (neutral $\{110\}$-planar $V_{4}$ chain, an electron spin $S=1) .^{7-9} I$-type defects such as P6 $\left(I_{2}\right)$, H8 (I-related), and B3/4/5 ( $\left.I_{3-4}\right)$ (Refs. 7-9) were not detected in our asimplanted samples or in the annealing study. In the next sample (b), a doublet signal with $S=1 / 2$ was observed. This doublet is ascribed as a hyperfine splitting (hfs) of ${ }^{19} \mathrm{~F}$ (nuclear spin $I=1 / 2$, natural abundance $=100 \%$ ). We named this "F0." Following to F0, other signals labeled "F1" to "F6" were observed in (c)-(e). These signals are most probably due to subsequent defects of F0 that are associated with more vacancies and/or $\mathrm{F}$ atoms. Basically, such a formation behavior was common to the deep implantations (b) - (d) and shallow implantations (e), except the absence of the F3 sig- nal in (e). A reason for this absence will be presented later.

The F0 spectrum was not detectable above $200 \mathrm{~K}$, and it exhibited a thermally activated reorientation behavior above $60 \mathrm{~K}$. Thus, in Fig. 2(a), the angular map of F0 is examined at $50 \mathrm{~K}$. The F0 center shows two separated patterns due to a ${ }^{19} \mathrm{~F}$ hfs with monoclinic- $I$ symmetry close to trigonal one. Just in the middle of the F0's patterns, a F2 pattern with the same symmetry was observed. Table I shows the determined spin-Hamiltonian (SH) parameters of F0 and F2. Both centers have similar $\mathrm{g}$ tensors of $P_{b}$-center-like $\left(g_{X} \approx g_{Y} \equiv g_{\perp}\right.$ $\approx 2.007, g_{\mathrm{Z}} \equiv g_{\|} \approx 2.001$, the $g_{\|}$axis is nearly parallel to $\langle 111\rangle$ ), indicating neutral $\mathrm{Si}$ dangling-bond (DB) nature for both origins. The F2 spectrum became larger with higher $\mathrm{F}$ doses [Fig. 1(d)] and still larger after annealing such that F0 decreased or vanished [Fig. 1(f)]. This suggests that F2 is a subsequent defect of $\mathrm{F} 0$ with more accumulation of $\mathrm{F}$ atoms. The major difference between F0 and F2 is ${ }^{19} \mathrm{~F}$ hfs. The ${ }^{19} \mathrm{~F}$ hyperfine tensor (A) of F0 shows an axial symmetry due to an $\mathrm{F} 2 p$ orbital that is parallel to the $g_{\|}$axis (i.e., the DB orbital). We constructed neutral $\mathrm{F}_{n} V_{2}$ models, based on all the data, for the origins of F0 $(n=1)$ and F2 $(n=2-5)$. The respective models are shown in Figs. 3(a) and 3(b). They can reasonably account for all the facts as follows. (1) $\mathrm{F} V_{2}$ [Fig. $3(\mathrm{a})$ ] contains a single neutral DB $(S=1 / 2)$ as well as (2) a single Si-F bond parallel to the DB orbital. (3) The $V_{2}$ distance $(0.59 \mathrm{~nm})$ allows a weak bond to form between the DB and $\mathrm{F}$ atom [Fig. 3(a)], extending the spin density over the ${ }^{19} \mathrm{~F}$ atom. (4) However, this weak bond will be broken if $\mathrm{F}$ atoms are then added into the vacancy [Fig. 3(b)]. (5) This mechanism controls the appearance of ${ }^{19} \mathrm{~F}$ hfs, resulting in the two distinguishable $\mathrm{F}_{n} V_{2}$ centers. (6) As similarly to $V_{2}$ (the G6 center) at $40-110 \mathrm{~K},{ }^{10}$ a thermally activated rearrangement can be expected for $\mathrm{F} 0$ among three equivalent DB-F pairs $\left(\mathrm{Si}_{1}-\mathrm{F}-\mathrm{Si}_{4}, \mathrm{Si}_{2}-\mathrm{F}-\mathrm{Si}_{5}\right.$, and $\left.\mathrm{Si}_{3}-\mathrm{F}-\mathrm{Si}_{6}\right),{ }^{11}$ causing the characteristic temperature dependence at $60-150 \mathrm{~K}$. At higher temperatures $(>200 \mathrm{~K}), \mathrm{F}$ atoms seemed to move inside the vacancy, resulting in the broadening and disappearance of F0 as well as a trigonal average of F2 [see Figs. 2(b) and 2(c), Table I]. Such a motion was also observed for hydrogen in a vacancy $(>200 \mathrm{~K}) .^{12}$

It is quite interesting to compare the F0/F2 centers (neutral $\mathrm{F}_{n} V_{2}$ ) with neutral hydrogen-vacancy defects ${ }^{12}$ such as

TABLE I. SH parameters of $\mathrm{F}_{n} V_{m}$ defects and related $V$-type defects. Total SH is given by $H=\mu_{\mathrm{B}} \mathbf{S} \cdot \mathbf{g} \cdot \mathbf{B}+\mathbf{S} \cdot \mathbf{D} \cdot \mathbf{S}+\mathbf{S} \cdot \mathbf{A} \cdot \mathbf{I}-g_{\mathrm{n}} \beta_{\mathrm{n}} \mathbf{I} \cdot \mathbf{B}$, where $\mathbf{g}$ is a $g$ tensor, $\mathbf{D}$ is a fine interaction tensor (excluded for spin-1/2 centers), and $\mathbf{A}$ is a hyperfine tensor (included only for F0 and S1a) (Refs. 7-9 and 12). Principal values of $\mathbf{A}$ and $\mathbf{D}$ are expressed in $\mathrm{mT}$. D and $\mathbf{g}$ tensors of F3 and P3 are identical. $(\mathrm{m})$ and $(\mathrm{t})$ denotes monoclinic- $I$ and trigonal symmetries. Measured temperatures are specified only for temperature-dependent spectra. Anneal and growth temperatures (signal was reduced or increased in these ranges, respectively), are also summarized.

\begin{tabular}{|c|c|c|c|c|c|c|c|}
\hline Center & $S$ & Tensor & $X$ & $Y$ & $Z(\|)$ & $\theta$ & Anneal/growth temperature \\
\hline \multirow[t]{2}{*}{$\mathrm{F} 0\left(\mathrm{~F} V_{2}^{0}\right)$} & \multirow[t]{2}{*}{$1 / 2(\mathrm{~m})$} & $\mathbf{g}(50 \mathrm{~K})$ & 2.0070 & 2.0067 & 2.0006 & $30.2^{\circ}$ & \multirow[t]{2}{*}{$220-280{ }^{\circ} \mathrm{C} /$ none } \\
\hline & & $\mathbf{A}\left({ }^{19} \mathrm{~F}\right)^{\mathrm{a}}$ & 4.23 & 4.15 & 6.27 & $210.4^{\circ}$ & \\
\hline $\mathrm{F} 2\left(\mathrm{~F}_{n} V_{2}^{0}\right)$ & $1 / 2(\mathrm{t})$ & $\mathbf{g}(295 \mathrm{~K})$ & 2.0081 & 2.0081 & 1.9995 & $35.26^{\circ}$ & $300-$ over $410^{\circ} \mathrm{C} / 200-300^{\circ} \mathrm{C}$ \\
\hline \multirow{2}{*}{$\mathrm{S} 1 \mathrm{a}\left(\mathrm{H} V_{2}^{0}\right)$} & $1 / 2(\mathrm{~m})$ & $\mathbf{g}(200 \mathrm{~K})$ & 2.0110 & 2.0100 & 2.0008 & $31.0^{\circ}$ & \multirow[t]{2}{*}{$180-280^{\circ} \mathrm{C} /$ none $^{\mathrm{b}}$} \\
\hline & & $\mathbf{A}\left({ }^{1} \mathrm{H}\right)^{\mathrm{a}}$ & 0.050 & 0.057 & 0.13 & $4.5^{\circ}$ & \\
\hline $\mathrm{F} 1\left(\mathrm{~F}_{n} V_{5}\right)$ & $1 / 2(\mathrm{~m})$ & $\mathbf{g}(295 \mathrm{~K})$ & 2.0088 & 2.0124 & 2.0046 & $17.5^{\circ}$ & $300-$ over $410^{\circ} \mathrm{C} / 200-300{ }^{\circ} \mathrm{C}$ \\
\hline $\mathrm{P} 1\left(V_{5}\right)$ & $1 / 2(\mathrm{~m})$ & $\mathbf{g}(320 \mathrm{~K})$ & 2.0091 & 2.0127 & 2.0050 & $15.0^{\circ}$ & $300-460{ }^{\circ} \mathrm{C} / 120-250^{\circ} \mathrm{C}^{\mathrm{d}}$ \\
\hline $\mathrm{F} 4$ & $1 / 2(t)$ & $\mathrm{g}$ & 2.0112 & 2.0112 & 2.0019 & $35.26^{\circ}$ & $250-$ over $410^{\circ} \mathrm{C} / 200-250^{\circ} \mathrm{C}$ \\
\hline
\end{tabular}

${ }^{\mathrm{a} A b s o l u t e}$ values.

${ }^{\mathrm{b}}$ Reference 12 .
${ }^{\mathrm{c}}$ References 7 and 9.

${ }^{\mathrm{d}}$ Reference 8 . 
(d) F1 DB

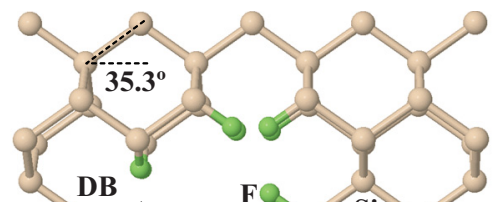
$17.5^{\circ}$

(c) $\mathrm{F} 3$

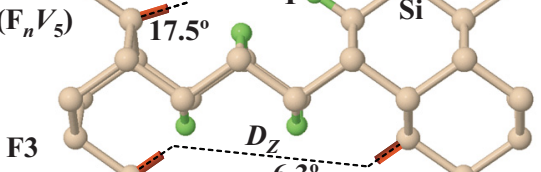

$\left(\mathrm{F}_{n} V_{4}\right)$

(b) F2 $\left(\mathrm{F}_{n} V_{2}\right)$

(a) Fo $\left(\mathrm{F} V_{2}\right)$

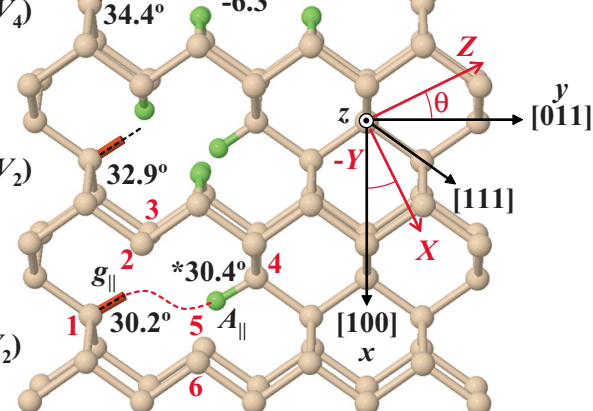

FIG. 3. (Color online) Atomic models for F0-F3 centers drawn in the $\mathrm{Si}(0 \overline{1} 1)$ plane. Cartesian coordinates $(x y z)$ and principal coordinates of $\mathrm{SH}$ tensors $(X Y Z)$ are also defined. Angles $\theta$ are shown for main principal directions $(Z$ or $\|)$ of $\mathbf{g}, \mathbf{A}$, and $\mathbf{D}$ tensors. F0, F1, and $\mathrm{F} 2$ have a single DB $(S=1 / 2)$, while F3 contains two DBs $(S=1)$. In (a), a weak bond between $\mathrm{DB}$ and $\mathrm{F}$ atom is drawn by a dashed line, which generates ${ }^{19} \mathrm{~F}$ hfs. ${ }^{*} \theta$ angle from the $-\boldsymbol{y}$ axis.

$\mathrm{H} V_{2}$ (the S1a center). Table I shows that their $g$ tensors belong to the same class. However, interestingly, there is a big difference between $\mathrm{H}$ and $\mathrm{F}$. Hydrogen and DB does not form a weak bond even in a monovacancy $(\mathrm{H} V)$. Therefore, both the $\mathrm{HV}$ and $\mathrm{H} V_{2}$ spectra revealed only very weak pointdipole interaction of ${ }^{1} \mathrm{H}$ nuclear spin $(I=1 / 2$, natural abundance $=99.9 \%),{ }^{12}$ which is one or two orders of magnitude weaker than the ${ }^{19} \mathrm{~F}$ hyperfine interaction of $\mathrm{FV} V_{2}\left[\mathbf{A}\left({ }^{1} \mathrm{H}\right)\right.$ values are 0.1-0.3 mT for $\mathrm{H} V$ (Ref. 12), and also see Table I for $\mathrm{H} V_{2}$ and $\left.\mathrm{F} V_{2}\right]$. The observed ${ }^{19} \mathrm{~F}$ hfs can be explained by the direct distribution of the spin density on ${ }^{19} \mathrm{~F}$. The formation of a weak bond between the DB and $\mathrm{F}$ atom enables this. Based on the standard linear combination of atomic orbitals analysis, ${ }^{13} 1.4 \%$ of the spin density (F $2 s$ $=0.25 \%$ and $\mathrm{F} 2 p=1.1 \%$ ) is estimated on the $\mathrm{F}$ atom for $\mathrm{F} 0$.

Note that the F0 center is one of the most primitive defects due to $\mathrm{F}$ implantation. In the $5 \times 10^{12} \mathrm{~F} / \mathrm{cm}^{2}$ sample [Fig. 1(b)], $48 \%$ of $\mathrm{F}$ atoms $\left(48 \% \times 5 \times 10^{12} \times 10 \mathrm{~F} / \mathrm{cm}^{2}\right)$ were consumed by F0 $\left(\mathrm{FV} V_{2}\right)$. Previous PAS studies also revealed $V_{2}$-type defects $(S$-parameter $=1.04)$ in their asimplanted samples. ${ }^{5,6}$

With an increased F dose, we could clearly detect the F1 and F3 spectra. A typical F3 spectrum was observed in the $5 \times 10^{13} \mathrm{~F} / \mathrm{cm}^{2}$ sample [Fig. 1(c)]. Its angular pattern [Fig. 2(b)] and SH parameters are indistinguishable from those of the P3 center $\left(V_{4}^{0}\right)$. However, in the isochronal anneal study (30 min at $25^{\circ} \mathrm{C}$ step), we found a higher thermal stability for $\mathrm{F} 3$ (annealed at $200-230{ }^{\circ} \mathrm{C}$ ) compared to P3 $\left(120-170{ }^{\circ} \mathrm{C} .{ }^{7,9}\right)$ Therefore, we suggest that the F3 center accumulates $\mathrm{F}$ atoms into $V_{4}$. Our proposed model for $\mathrm{F} 3$ is shown in Fig. 3(c). Since $S=1$ for F3, there should be two neutral $\mathrm{Si}$ DBs separated by the $V_{4}$ distance $(0.97 \mathrm{~nm})$. Since these DBs could be easily charged with doping for the case of $\mathrm{P} 3{ }^{7}$ the $\mathrm{F} 3$ spectrum could disappear in the $n$ - and $p$-type samples [Fig. 1(e)]. It is notable that $\mathrm{F}_{n} V_{4}(\mathrm{~F} 3)$ was less stable than $\mathrm{F}_{n} V_{2}(\mathrm{~F} 2)$, because the $\mathrm{F} 2$ spectrum remained after F3 completely vanished [at 225 and $300{ }^{\circ} \mathrm{C}$, Fig. 1(f)]. $\mathrm{F}_{n} V_{4}$ seems to be decomposed into $\mathrm{F}_{n} V_{2}$.

In the isochronal annealing study, the most stable center was "F1." A typical spectrum for it appears in Fig. 1(f). The angular map of F1 is clearly traced in Fig. 2(c). The determined $\mathrm{g}$ tensor of $\mathrm{F} 1$ was close to that of the P1 center. ${ }^{7,8}$ The P1 center has a single neutral DB $(S=1 / 2)$ and has been identified as a negative nonplanar $V_{5}$ cluster. ${ }^{8}$ Based on the $\mathrm{P} 1$ model, we assign the $\mathrm{F}_{n} V_{5}$ model to the origin of $\mathrm{F} 1$, as shown in Fig. 3(d). In the $5 \times 10^{14}-\mathrm{F} / \mathrm{cm}^{2}$ sample, the density of $\mathrm{F} 1$ was maximized to $1.3 \times 10^{14} / \mathrm{cm}^{2}$ after $300{ }^{\circ} \mathrm{C}$ anneal. In this situation, if one assumes $50 \%$ decoration of $\mathrm{F}$ atoms for $\mathrm{F} 1$ (six $\mathrm{F}$ atoms $\left./ V_{5}\right), 52 \%$ of implanted $\mathrm{F}$ atoms $(52 \%$ $\times 5 \times 10^{14} \times 6 \mathrm{~F} / \mathrm{cm}^{2}$ ) would accumulate into $\mathrm{F} 1$. Further annealing decreased the F1 centers, however, they were stable and remained by $8 \times 10^{14} / \mathrm{cm}^{2}$ at $410{ }^{\circ} \mathrm{C}$. In previous PAS studies, the maximum vacancy size was found to be about $V_{4}(S$-parameter $=1.05)$ after $700{ }^{\circ} \mathrm{C}$ annealing. ${ }^{5}$ The $\mathrm{F} 1$ center is the most probable candidate for such large, stable defects.

In summary, using EPR, we found a variety of $\mathrm{F}_{n} V_{m}$ defects (F0-F6) in F-implanted $\mathrm{Si}$ and in the subsequent annealing study. The most primitive center was $\mathrm{FV}_{2}$ (the F0 center) observed in the initial stage of $\mathrm{F}$ implantation and this center revealed a characteristic ${ }^{19} \mathrm{~F}$ hfs. With increasing the $\mathrm{F}$ dose or annealing the sample, other $\mathrm{F}_{n} V_{m}$ defects with more accumulation of $\mathrm{F}$ atoms were observed. The most stable center was the F1 center $\left(\mathrm{F}_{n} V_{5}\right)$, and the next one was the F2 center $\left(\mathrm{F}_{n} V_{2}\right) . \mathrm{F}_{n} V_{3}$ defects were not found. $\mathrm{F}_{n} V_{4}$ defects were probably detected as the F3 center.

We thank J. Ohsaki (University of Tsukuba) for his help in experimental works and also S. Sakurai (Elpida Memory, Inc.) for sample preparations.

${ }^{1}$ M. Diebel and S. T. Dunham, Phys. Rev. Lett. 93, 245901 (2004).

${ }^{2}$ Y. I. Kim, K. H. Yang, and W. S. Lee, IEEE Int. Reliab. Phys. Symp. Proc. 2004, 667; K. Ohyu, T. Umeda, K. Okonogi, S. Tsukada, M. Hidaka, S. Fujieda, and Y. Mochizuki, Tech. Dig. - Int. Electron Devices Meet. 2006, 389.

${ }^{3}$ G. M. Lopez, V. Fiorentini, G. Impellizzeri, S. Mirabella, and E. Napolitani, Phys. Rev. B 72, 045219 (2005).

${ }^{4}$ G. M. Lopez and V. Fiorentini, Appl. Phys. Lett. 89, 092113 (2006).

${ }^{5}$ X. D. Pi, V. P. Burrows, and P. G. Coleman, Phys. Rev. Lett. 90, 155901 (2003).

${ }^{6}$ P. J. Simpson, Z. Jenei, P. Asoka-Kumar, R. R. Robison, and M. E. Law, Appl. Phys. Lett. 85, 1538 (2004).

${ }^{7}$ Y. H. Lee, Y. M. Kim, and J. W. Corbett, Radiat. Eff. 15, 77 (1972).

${ }^{8}$ Y. H. Lee and J. W. Corbett, Phys. Rev. B 9, 4351 (1974).

${ }^{9}$ D. Pierreux and A. Stesmans, Phys. Rev. B 71, 115204 (2005).

${ }^{10}$ G. D. Watkins and J. W. Corbett, Phys. Rev. 138, A543 (1965).

${ }^{11}$ In this model, we predict a "cooperative" jump of a DB and a F atom. This feature will be also as a consequence of the weak-bond formation in $\mathrm{F} V_{2}$. In fact, the $\mathrm{H} V_{2}$ center, which has an atomic structure just analogue to $\mathrm{FV}_{2}$, did not show such a motional effect (Ref. 12), most probably because there was no weak bond between a $\mathrm{DB}$ and a $\mathrm{H}$ atom.

${ }^{12}$ B. Bech Nielsen, P. Johannesen, P. Stallinga, and K. Bonde Nielsen, Phys. Rev. Lett. 79, 1507 (1997); P. Stallinga, P. Johannesen, S. Herstrøm, K. B. Nielsen, B. Bech Nielsen, and J. R. Byberg, Phys. Rev. B 58, 3842 (1998).

${ }^{13}$ J. A. Weil, J. R. Bolton, and J. E. Wertz, Electron Paramagnetic Resonance (Wiley, New York, 1994). 